[Bull. Agr. Chem. Soc. Japan, Vol. 24, No. 1, p. 59 65, 1960]

\title{
Studies on Transfer of Antiseptics to Microbes and their Toxic Effect
}

\section{Part I. Accumulation of Acid Antiseptics in Yeast Cells}

\author{
By Satoru ОкА \\ Food Indusirial Experiment Station, Hiroshima Prefecture
}

Received April 25, 1959

\begin{abstract}
In the medium of the low pH value, acid antiseptics (salicylic, benzoic, dehydroacetic and sorbic acid) transfer very rapidly from the medium to yeast cells, and these antiseptics are accumulated in the cells.

The transferred quantity is in equilibrium with the concentration of the undissociated antiseptics in the medium, and the ratio of the transferred quantity to the concentration of the total antiseptics in the medium is limited by the $\mathrm{pH}$ in the medium. Accordingly, it has been considered that the $\mathrm{pH}$ value affects the transfer ratio and results in the variation of the toxic effect of the antiseptics.

In connection with this, not only the ionization equilibrium, but also the adsorption of the undissociated antiseptics on the solid phase of the cell has been assumed to be related to the accumlatian of the antiseptics.
\end{abstract}

In order that antiseptics inhibit the growth of microbes, it is essential to transfer them from a medium to microbe cells, and thus the toxic effect will be influenced by the quantity of the antiseptics transferred to the cells.

Usually, the toxic effect of antiseptics on microbes in food preservation is estimated by the concentration required to bring about a certain response. However, no information can be obtained by this method on the net toxic activity because the quantity transferred to the microbes remained unknown.

It is well known that the toxic effect of acid antiseptics such as salicylic, benzoic, dehydroacetic and sorbic acid, which have an ionization constant in the order of $10^{-3} \sim 10^{-5}$, varies with the hydrogen ion concentration of the medium, and that the toxic effect is proportional to the concentration of the undissociated antiseptics. Accordingly, it has been assumed that the undissociated fraction of acid antiseptics is the chief substance, and in many cases the only substance having a relation to the antiseptic effect ${ }^{1 \sim 4}$.

Recently, Masuo and Okabayashi ${ }^{\text {s) }}$ have been suggested that only the undissociated molecules of dehydroacetic acid exclusively permeate into microbe cells and that the concentration of the undissociated molecules is proportional to the toxic effect. The s.rme mechanism was supported by Nomoto et al. ${ }^{6}$ in connection with the toxic effect of sorbic acid.

Conway and Downy ${ }^{7)}$ have obtained an interesting result that only the undissociated molecules of acetic acid selectively diffuse into yeast cells, and that the diffused acid is accumulated in the inner cell fluid in the ionized form. It seems that this mechanism can also be applied

1) P. G. F. Vermast, Biochem. Z., 1921, 125.

2) S. Tersumoto, J. Agr. Chem. Soc. Japan, 9, 388, 563, 761, 1284 (1933)

3) O. Rahn and J.E. Cona, Ind. Eng. Chem, Ind. Ed., 36 , 185 (1944).

4) G. I. Huntington and O. Rahn, J. Batt., 50, 49 (1945).

5) E. Masuo and T. Okabayashi, Annnal Report of Sbionogi Re search Laboratory, No. 3, 101 (1953).

6) M. Nomoto, Y. Narahashi and Y. Niikawa, J. Agr. Chem. Sor. Japan, 29, 805 (1955).

7) E. J. Conway and M. Downy, Biorbem. J., 47, 355 (1950). 
to the transfer of acid antiseptics, though the mechanism of the selective diffusion is a matter of speculation.

As mentioned above, only a little information has been obtained on the transfer mechanism of acid antiseptics and on the relation between the transfer and their toxic effect.

As the result of the present work, it has been considered that the $\mathrm{pH}$ value limits the ratio of the transferred quantity to the concentration of the total antiseptics in the medium and results in the variation of the toxic effect of the antiseptics, and that not only the ionization equilibrium, but also the adsorption of the undissociated antiseptics on the solid phase of the cell is related to the accumulation of antiseptics.

\section{MATERIALS AND METHODS}

Yeast cells Bakers' yeast was repeatedly washed with tap water and centrifuged for twenty minutes at a rate of 4,000 rotations per minute. The quantity of water which wetted the surface of the centrifuged yeast was estimated by Conway's inulin space method ${ }^{8)}$. The constitution of the centrifuged yeast is shown in Table $\mathbf{I}$.

\section{TABle I. Constitution of Gentrifuged Yeast $(\%)$

Cells 78.3 \\ Dry matter $\quad 27.1$ \\ Water in cells $\quad 51.2$ \\ Wetting water out of cells $\quad 21.7$}

Acid antiseptics Salicylic acid (m.p. $157^{\circ} \sim 159^{\circ}$ ), benzoic acid (m.p. $122^{\circ}$ ), dehydroacetic acid (m.p. 108 ${ }^{\circ}$ ) and sorbic acid (m.p. $133^{\circ}$ ) were used in the form of the sodium salt.

Buffer solution McIlvaine's buffer solution was used, here the ionic strength of the solution was adjusted to 0.42 with sodium chloride.

Determination of transferred quantity A definite quantity of the centrifuged yeast was suspended in the buffer solution, and a definite quantity of an antiseptic and distilled water was added to the suspension. Finally, the buffer solution was diluted to a quarter of the original concentration. The quantity of the yeast cells in the final mixture was 1 per cent in the case of salicylic acid, and was 5 per cent in the cases of other antiseptics. The temperature of the suspension was held constant. After definite intervals, the mixture 8) E. J. Conway and M. Downy, Biochem. J., 47, 347 (1950). was taken out and centrifuged. Then, the concentration of the antiseptic in the supernatant was determined and its $\mathrm{pH}$ value was measured. Simultaneously, a blank experiment was carried out under the same condition.

The "transferred quantity", a (m-mol./kg-cell), of the antiseptic was calculated by equation (1). Here, $C_{o}$ and $C_{m}$ (m-mol./kg-water)

$$
a=\left(C_{o}-C_{m}\right) V / M
$$

are the concentrations of an antiseptic in the medium before and after suspending the yeast, respectively, and $V(\mathrm{~kg})$, the final quantity of the solvent water in the medium, and $M(\mathrm{~kg})$, the weight of the suspended yeast cells.

The "transfer ratio", $A$ (kg-water $/ \mathrm{kg}$-cell), was calculated by equation (2).

$$
A=a / C_{m}
$$

Determination of antiseptics in medium The supernatant of the mixture was diluted with 0.2 per cent aqueous hydrochloric acid, and the optical extinction of this solution was measured by Shimizu ultravioletspectrophotometer. The blank test was also carried out in the same manner. Then, the exact extinction of the antiseptic in the solution was given by the difference of both values.

Since the extinction value of the antiseptics used in this experiment was proportional to the concentration in this condition, the concentration of the antiseptics in the supernant was calculated by their molar extinction coefficient and the dilution ratio of the supernatant. Wave-length and molar extinction coefficient are given in Table II

Measurement of $\mathrm{pH}$ value The $\mathrm{pH}$ value of the medium was measured by Tōyō Roshi glass-electrode $\mathrm{pH}$ meter.

Table II. Optical Absorption Data of ACID ANTISEPTICS IN 0.2 PERCENT AQEOUS HYDROCHLORIC ACID SOLUTION

$\begin{array}{ccc}\begin{array}{c}\text { Acid } \\ \text { antiseptic }\end{array} & \begin{array}{l}\text { Wavelength } \\ \text { at maximum } \\ \text { absorption } \\ (\mathrm{m} \mu)\end{array} & \begin{array}{l}\text { Molar } \\ \text { extinction } \\ \text { coefficient }\end{array} \\ \text { droacetic acid } & 236.5 & 8,370 \\ \text { ic acid } & 230.0 & 11,580 \\ \text { acid } & 307.0 & 13,060 \\ & 260.0 & 25,400\end{array}$

\section{RESULTS}

Change of transfer ratio with suspending time Changes of the transfer ratio with suspending time were subsequently investigated. The re- 
Table III. Change of Transfer Ratio with Suspending Time

Transfer ratio

Suspending time (min.)

Dehydroacetic acid

Sorbic acid

Benzoic acid

Salicylic acid

\begin{tabular}{cccccc}
\multicolumn{7}{c}{ Transfer ratio } \\
5 & 10 & 15 & 30 & 60 & 120 \\
7.50 & 7.50 & 7.34 & 7.42 & 7.34 & 7.44 \\
16.5 & 17.0 & 17.5 & 17.9 & 17.5 & 18.3 \\
31.7 & 36.4 & 35.9 & 36.8 & 34.2 & 35.5 \\
72.1 & 72.5 & 70.4 & 72.2 & 72.9 & 71.2
\end{tabular}

Yeast cells were suspended in the buffer solution of $\mathrm{pH} 3.20$ containing of an acid antiseptic in $1 \mathrm{~m}-\mathrm{mol} / \mathrm{kg}$-water at $30^{\circ} \mathrm{C}$.

sults are shown in Table III. The transfer of the antiseptics seems to be practically completed in less than five minutes at $\mathrm{pH} 3.20$.

Influence of $\mathbf{p H}$ on transfer The transfer ratio changed according to the $\mathrm{pH}$ value in the me-

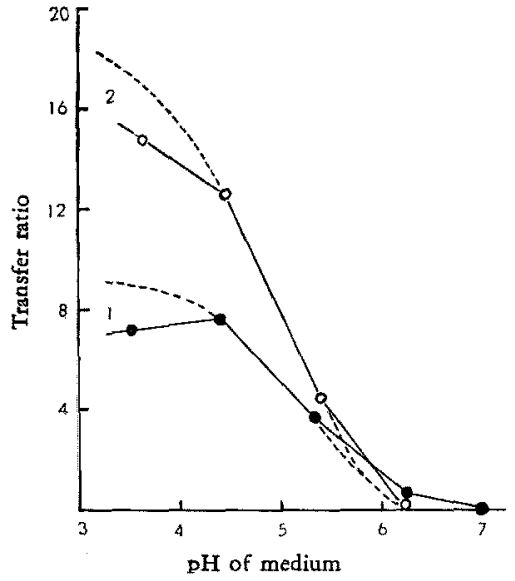

FIG. 1. Change of Transfer Ratio of Acid Antiseptics by $\mathrm{pH}$ of Medium

1: Dehydroacetic acid (pK 5.1) 3: Benzoic acid (pK 4.2)

2: Sorbic acid ( $\mathrm{pK} 4.8$ )

4: Salicylic acid (pK 3.0)

Yeast cells were suspended in the buffer solution containing an acid antiseptic in $1 \mathrm{~m}$-mol. $/ \mathrm{kg}$-water for one hour at $30^{\circ} \mathrm{C}$. Actual lines show the experimental data. Dotted lines show the theoretical ratio of the undissociated fraction of the antiseptics. Latters were enlarged to cross on the $\mathrm{pH}$ point of the corresponding experimental courves.

TABLE IV. INFLUENCE OF pH OF MEDIUM ON TRANSFER AND REMOVEMENT OF ACID ANTISEPTICS

\section{Antiseptic}

Antiseptic added

Residual at $\mathrm{pH} 3.15^{13}$

Residual at $\mathrm{pH} 7.02^{2)}$

In neutralized medium ${ }^{3)}$

$\mathrm{pH}$ of neutralized medium

\section{Quan}

Dehydroacetic acid

20.0

15.3

19.8

20.1

6.83 dium as shown in Fig. 1. On the other hand, the ratio of the undissociated fraction to the

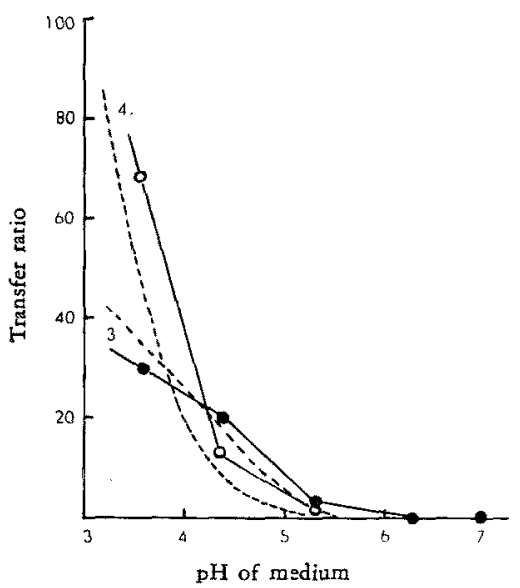

Yeast cells were suspended into $10 \mathrm{ml}$ of the medium containing $2 \mu \mathrm{mol}$. of an acid antiseptic at $\mathrm{pH} 3.15$ or 7.02 . After one hour, the residual quantity of the antiseptic ${ }^{1}{ }^{22}$ was determined.

The suspension at $\mathrm{pH} 3.15$ was neutralized with sodium hydroxide to $\mathrm{pH} 6.8 \sim 7.2$ and was allowed to stand for one hour at $30^{\circ} \mathrm{C}$. Then, the quantiry of the antiseptic in the mediumas was determined. 
worthy that the shape of the observed curves seems to coincide with that of the calculated curves. From this result, it can be concluded that the transferred quantity is in equilibrium with the concentration of the undissociated antiseptics in the medium and the transfer ratio is thus limited by the $\mathrm{pH}$ in the medium.

At the low $\mathrm{pH}$ value of the medium a large amount of the antiseptics is transferred to the cells. When the medium was neutralized and was allowed to stand for one hour, the antiseptics in the cells were easily and perfectly removed as shown in Table IV. This result indicates that no antiseptics decomposed, and that the transfer equilibrium is controlled by the $\mathrm{pH}$ value of the medium.

Change of transfer ratio by equilibrium concentration The relation of the equilibrium concentration in the medium with the transferred quantity is shown in Table $V$.

From the result shown in Table $\mathrm{V}$, it is seen that the transferred is not linearly proportional to the equilibrium concentraiton, and that the transfer ratio is reduced as the equilibrium concentration is increased.

The plot of the logarithm of the transferred quantity versus the logarithm of the equilibrium concentration gives a straight line as shown in Fig. 2. This relation can be expressed by equation (3),

$$
a=k\left(C_{m}\right)^{n}
$$

where $k$ and $n$ are the constants concerning each antiseptic, $a$ the transferred quantity, and $C_{m}$ the equilibrium concentration of an antiseptic. It is of interest that equation (3) corresponds to Freundlich's adsorption isotherm.

Dependence of transfer on temperature The relation of the transferred quantity to the equilibrium concentration was examined at various temperatures, and the values of $k$ and $n$ at various temperatures are given in Table VI. These values seem to vary with the temperature.

\section{DISCUSSION}

In the medium with the low $\mathrm{pH}$ value, the acid antiseptics transfer very rapidly from the medium into the yeast cell, and the antiseptics are accumulated in the cell (Tables III and V). The transferred quantity is in equilibrium with the concentration of the undissociated antiseptics in the medium, and therefore the transfer ratio of the antiseptics is limited by the $\mathrm{pH}$ in the

Table V. Change of Transfer Ratio by Equilibrium Concentration

\begin{tabular}{|c|c|c|c|c|c|}
\hline Antiseptic & & $\begin{array}{c}\text { Initial } \\
\text { concentration } \\
(\mathrm{m}-\mathrm{mol} / \mathrm{kg} \text {-water })(\mathrm{n}\end{array}$ & $\begin{array}{l}\text { Equilibrium } \\
\text { concentration } \\
\text { m-mol./kg-water) }\end{array}$ & $\begin{array}{c}\text { Transferred } \\
\text { quantity } \\
\text { (m-mol./kg-cell) }\end{array}$ & $\begin{array}{l}\text { Transfer } \\
\text { ratio }\end{array}$ \\
\hline \multirow{5}{*}{ Dehydroacetic acid } & \multirow{4}{*}{ (cells : $5 \%$ ) } & $\quad 0.25$ & 0.168 & 1.64 & 9.76 \\
\hline & & 0.50 & 0.350 & 3.00 & 8.57 \\
\hline & & 1.00 & 0.729 & 5.42 & 7.43 \\
\hline & & 2.00 & 1.528 & 9.44 & 6.17 \\
\hline & \multirow{4}{*}{ (cells : $5 \%$ ) } & 0.25 & 0.106 & 2.88 & 27.2 \\
\hline \multirow{3}{*}{ Sorbic acid } & & 0.50 & 0.239 & 5.22 & 21.8 \\
\hline & & 1.00 & 0.729 & 9.32 & 17.3 \\
\hline & & 2.00 & 1.258 & 14.84 & 11.8 \\
\hline \multirow{4}{*}{ Benzoic acid } & \multirow{4}{*}{ (cells: $5 \%$ ) } & 0.25 & 0.060 & 3.80 & 63.3 \\
\hline & & 0.50 & 0.169 & 6.62 & 39.1 \\
\hline & & 1.00 & 0.357 & 12.9 & 36.1 \\
\hline & & 2.00 & 0.874 & 22.5 & 25.7 \\
\hline \multirow{4}{*}{ Salicylic acid } & \multirow{4}{*}{ (cells: $1 \%$ ) } & 0.25 & 0.107 & 14.3 & 133.5 \\
\hline & & 0.50 & 0.244 & 25.6 & 104.8 \\
\hline & & 1.00 & 0.579 & 42.1 & 72.8 \\
\hline & & 2.00 & 1.370 & 63.0 & 46.0 \\
\hline
\end{tabular}

Yeast cells were suspended in the buffer solution of $\mathrm{pH} 3.20$ containing an acid antiseptic for one hour at $30^{\circ} \mathrm{C}$. 
Tarle VI. Dependence of Transfer of Acid Antiseptics on Temperature

Temperature $\left({ }^{\circ} \mathrm{C}\right)$

Dehydroacetic acid

Sorbic acid

Benzoic acid

Salicylic acid

\begin{tabular}{lll} 
& $k$ & \\
\hline 30 & 20 & 10 \\
6.9 & 10.0 & 8.3 \\
13 & 16 & 14 \\
25 & 27 & 25 \\
56 & 51 & 59
\end{tabular}

\begin{tabular}{ccc}
\multicolumn{3}{c}{$n$} \\
30 & 20 & 10 \\
0.78 & 0.76 & 0.70 \\
0.68 & 0.65 & 0.53 \\
0.68 & 0.54 & 0.46 \\
0.61 & 0.60 & 0.57
\end{tabular}

The values of $k$ and $n$ correspond with the coastants in equation (3). The experimental conditions were the same as is shown in Table $\mathrm{V}$ except the temperature of the suspension.

medium (Fig. 1). On the other hand, it has well been known that the toxic effect of the antiseptics is proportional to the ratio of the undissociated fraction to the total quantity of the antiseptics in the medium ${ }^{1 \sim 6)}$. Accordingly, it is considered that the $\mathrm{pH}$ value affects the transfer ratio and results in the variation of the toxic effect of the antiseptics.

With respect to the case that only the undissociated acid is related to the transfer to the cell, Conway and Downy ${ }^{7)}$ have proposed equation (4). (In order to simplify problem, the correction for ionic strength was omitted from the original formula.)

$$
R=C_{l} S / C_{m}=S\left(1+K / h_{l}\right) /\left(1+K / h_{m}\right)
$$

Here, $C_{l}$ and $C_{m}$ are the concentrations of the acid in and out of the cell, $K$ the ionization constant and $S$ the quantity of the solvent water in the cell which was evaluated as great as $0.7(1 / \mathrm{kg} \text {-cell })^{7}$. In that case, the $\mathrm{pH}$ value in the cell is lowered by accumulation of the acid, and the decrease in the $\mathrm{pH}$ value is evaluated and corrected by the average buffering of the cell fluid (63m-equiv./1-fluid) ${ }^{7}$. Thus, the $\mathrm{pH}$ value in the resting bakers' yeast cell has been evaluated to be 5.81 from the data with acetic acid and is in good agreement with the value obtained from direct determination of the $\mathrm{pH}$ value of frozen and thawed yeast ${ }^{\text {? }}$.

Supposing that the value of $C_{b} S$ in equation (4) corresponds to the transferred quantity, $a$, in the present experiment, the value of $R$ will correspond to the transfer ratio, $A$. Thus, this mechanism can be applied to the transfer of acid antiseptics, and the change of the transfer ratio of the antiseptics with $\mathrm{pH}$ in the medium
(Fig. 1) and the trend that the smaller is the value of $\mathrm{pK}$ of the antiseptics, the greater is the maximum value of the transfer ratio (Fig. 1 and Table V) can be expressed by equation (4).

On the other hand, the relation between the transferred quantity and the equilibrium concentration obeyed Freundlich's adsorption isotherm (Fig. 2), and the values of $k$ and $n$ in the isotherm were varied with temperature (Table VI). From these facts, it may be assumed that the adsorption has a relation to the transfer and accumulation. However, the fact that the value of $n$ in the isotherm is smaller

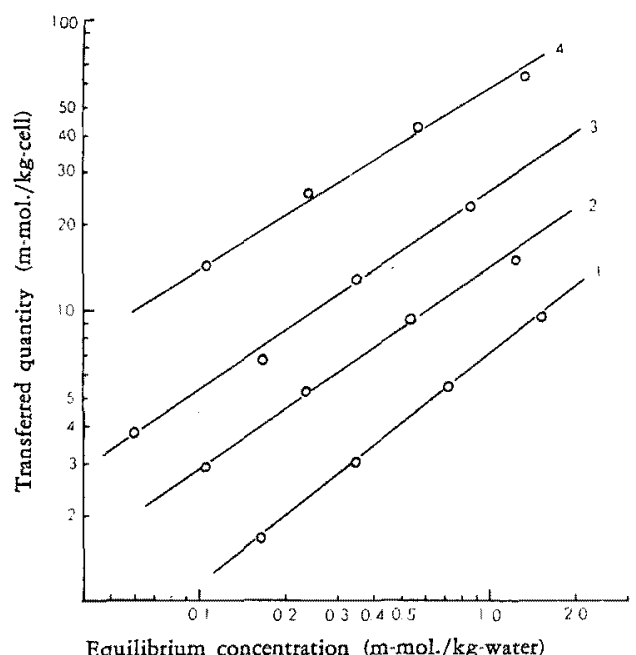

FIG. 2. Relation between Transferred Quantity and Equilibrium Concentration of Acid Antiseptics ( $\mathrm{pH} 3.20$ )
1: Debydroacetic acid
2: Sorbic acid
3: Benzoic acid 
than 'one' is considered to depend partially upon the decrease in the $\mathrm{pH}$ in the cell owing to the accumulation of the antiseptics. Also, the influence of temperature on the values of $k$ and $n$ in the isotherm may be elucidated from the fact that the $\mathrm{pH}$ in the cell is influenced by the temperature. This is because the ionization constant of the antiseptics changes with temperature.

As mentioned above, equation (4) is apparently applicable to the present data. Then, the original $\mathrm{pH}$ value in the cell was evaluated by substituting the data given in Table $\mathrm{V}$ and Conway's $S$ value (0.7) in equation (4) and by correcting the $\mathrm{pH}$ value which was decreased by the accumulation of the antiseptics. also the other possible mechanism such as adsorption or partition has a relation to the accumulation of the antiseptics. Supposing that the adsorption on the cell membrane and dissolution in the lipid of the cell are related to the selective transfer of the undissociated antiseptics, the fact that antiseptics transfer very rapidly to the cell (Table III) will be easily elucidated, while it cannot be elucidated by mere diffusion through the cell membrane. (Sugars and polyalcohols which have the same order of molecular weight as the present antiseptics hardly diffuse into the cell.) As the content of the lipid in the yeast usually does not exceed a low percentage, the quantity of the antiseptics remaining in the lipid phase by partition may be negligibly

Table VII. Value of pH and Quantity of Solvent Water in Yeast Gell

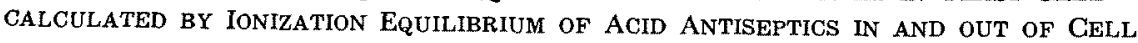

\begin{tabular}{|c|c|c|c|c|c|c|}
\hline Antiseptic & & $\begin{array}{c}C_{m}^{1)} \\
\text { (m-mol./kg-water) }\end{array}$ & $A^{13}$ & $\begin{array}{c}\mathrm{pH} \\
\text { (calc.) }\end{array}$ & $\begin{array}{c}\mathrm{pH}^{2)} \\
\text { (original) }\end{array}$ & $S$-value ${ }^{3)}$ \\
\hline \multirow{2}{*}{ Dehydroacetic acid } & \multirow{2}{*}{$(\mathrm{pK} 5.1)$} & jo.168 & 9.76 & 6.23 & 6.26 & 1.7 \\
\hline & & $\{1.528$ & 6.17 & 6.00 & 6.19 & 1.3 \\
\hline \multirow{2}{*}{ Sorbic acid } & \multirow{2}{*}{$(\mathrm{pK} 4.8)$} & $\{0.106$ & 27.2 & 6.29 & 6.35 & 2.2 \\
\hline & & $\{1.258$ & 11.8 & 5.91 & 6.23 & 1.3 \\
\hline \multirow{2}{*}{ Benzoic acid } & \multirow{2}{*}{$(\mathrm{pK} 4.2)$} & $\{0.060$ & 63.3 & 6.19 & 6.28 & 1.7 \\
\hline & & $\{0.874$ & 25.7 & 5.79 & 6.30 & 1.3 \\
\hline \multirow{2}{*}{ Salicylic acid } & \multirow{2}{*}{$(\mathrm{pK} 3.0)$} & $\{0.107$ & 133.5 & 5.63 & 5.95 & 0.92 \\
\hline & & 11.370 & 46.0 & 5.23 & 6.66 & 1.2 \\
\hline Acetic acid (author) & & 5.50 & 6.09 & 5.42 & 5.84 & 0.73 \\
\hline Acetic acid (Conway) & $(\mathrm{pK} 4.7)$ & & & 5.44 & 5.81 & 0.70 \\
\hline
\end{tabular}

However, the evaluated $\mathrm{pH}$ values in the cell given in Table VII are greater than those obtained with acetic acid, though they were expected to be equal (5.81). From the assumption that the $\mathrm{pH}$ value of yeast is equal to that of Conway's yeast (5.81), the value of $S$ given in the last column of Table VII exceeds ' 0.7 '. But, this evaluated value is fabulously great, because the maximum value of $S$ should be smaller than ' 0.7 ', judging from the content of water in the yeast cell (Table I).

From this fact, it seems that not only the ionization equilibrium in the aqueous phase, but small, and thus the adsorbed quantity on the solid phase of the cell becomes important matter.

On basis of these considerations, it is most reasonable to assume that the main part of the transferred antiseptic exists in two states: one is the dissolved antiseptic in the inner cell fluid, which is in an ionization equilibrium, which is a function of $\mathrm{pH}$, as proposed by Conway and Downy ${ }^{7)}$, and the other is the adsorbed antiseptic on the solid phase of the cell.

Investigation of the role of the dissolved and adsorbed antiseptic on the toxic effect will be presented in the following report. 
Acknowledgements The author wishes to express his sincere thanks to Emeritus Prof. R. Sasaki and Prof. Y. Sakurai of Tokyo University for their interest in his work, and also to Dr. C. Hata, President of this Institute, for his support and encouragement. The author is greatly indebted to Dr. M. Fujimaki, Dr. S. Okimasu, Mr. R. Nōmi and Mr. K. Shimizu for their kind advice.

[Bull. Agr. Chem. Soc. Japan, Vol. 24, No. 1, p. 65 68, 1960]

\title{
Wood Extractives
}

\author{
Part IX. A New Diterpene Alcohol from Cryptomeria japonica D. Don \\ By Tamio Kondo, Hiroyuki Immaura and Motoshige Suda \\ Government Forest Experiment Station, Meguro, Tokyo \\ Received April 28, 1959
}

\begin{abstract}
Phyllocladanol, a saturated tetracyclic diterpene alcohol present in the neutral portion of methanol extract from Cryptomeria japonica, is shown to readily dehydrate to phyllocladene, and the constitution (I) is proposed. Occurrence of a further compound, isophyllocladene, in steamvolatile material of the extract is described.
\end{abstract}

In continuation of earlier work ${ }^{1)}$ an unknown compound, $\mathrm{C}_{20} \mathrm{H}_{34} \mathrm{O}$, m. p. $182 \sim 183^{\circ},[\alpha]_{D}^{15}+$ $14.52^{\circ}$, obtained from the neutral portion of wood resin of Cryptomeria japonica D. Don, has been examined. In part VIII' ${ }^{1>}$ of this series, an isolation of this compound has been described in detail. This compound, called phyllocladanol, is not apparent to have been previously isolated. Phyllocladanol is colorless needles being soluble in ether and chloroform, less soluble in methanol, and give a negative LiebermannBurchard reaction. In view of this molecular formula and co-existence in wood with other diterpenoids, e.g. ferruginol and xanthoperol, it is probable that phyllocladanol is one of diterpenes having a polycyclic carbon skeleton.

Phyllocladanol contains one hydroxyl group which is unreactive, not being acylated under ordinary conditions. It exhibits strong infrared

1) T. Kondo, H. Imamura and M. Suda, This Bulletin, 23, 233 (1959). absorptions at 3436 and $1126 \mathrm{~cm}^{-1}$ which are assigned to the hydroxyl group. Treatment with acetic anhydride an anhydrous sodium acetate under reflux unexpectedly gives a compound, m. p. $91 \sim 93^{\circ}$, corresponding to a mixture of monoacetyl derivative and its dehydration product. Having attempted mild oxidation with chromic acid the compound is recovered unchanged, in a small quantity. The hydroxyl group is accordingly considered to be tertiary.

In reference to the nature of carbon skeleton of the diterpene alcohol it is considered to have a tetracyclic structure as mentioned below. From the negative tetranitromethane reaction, no absorption of hydrogen on catalytic hydrogenation using platinum oxide catalyst in a glacial acetic acid solution, and the absence of a characteristic infrared absorption band for the double bond in the $1700 \sim 1600 \mathrm{~cm}^{-1}$ region, it is shown that phyllocladanol is a saturated compound. In view of the molecular formula and 